\title{
The Numerous Benefits of Social Media for Medicine. Comment on "Documenting Social Media Engagement as Scholarship: A New Model for Assessing Academic Accomplishment for the Health Professions"
}

\author{
John Alan Gambril ${ }^{1,2}$, MD; Carter J Boyd ${ }^{3}$, MBA, MD; Jamal Egbaria ${ }^{4}$, MD \\ ${ }^{1}$ Department of Internal Medicine, Ohio State University Wexner Medical Center, Columbus, OH, United States \\ ${ }^{2}$ Nationwide Children's Hospital, Columbus, OH, United States \\ ${ }^{3}$ Hansjörg Wyss Department of Plastic Surgery, NYU Langone Health, New York, NY, United States \\ ${ }^{4}$ University of Alabama at Birmingham School of Medicine, Birmingham, AL, United States
}

\section{Corresponding Author:}

John Alan Gambril, MD

Department of Internal Medicine

Ohio State University Wexner Medical Center

$410 \mathrm{~W} 10$ th Ave

Columbus, OH, 43210

United States

Phone: 12059362955

Email: alangambril@gmail.com

\section{Related Article:}

Comment on: https://www.jmir.org/2020/12/e25070/

(J Med Internet Res 2021;23(6):e27664) doi: 10.2196/27664

\section{KEYWORDS}

social media; medical education; internet; academic medicine; promotion; tenure; health professions; scholarship; medicine; research; accomplishment; crowd source; contribution; innovation; education; dissemination

In their recent paper, Acquaviva et al [1] developed a set of guidelines to standardize curriculum vitae (CV) documentation of scholarly contributions made via social media platforms. Appropriately, the authors crowd-sourced contributions for the guidelines from the popular social media platform Twitter. Their work underscores the value of social media in idea sharing, highlights the growing role of online platforms in medical education, and signifies an important step in modernizing academic recognition to match the modernization of current medical learners.

Social media offers numerous scholarly and professional benefits $[2,3]$. These platforms have grown popular among the academic and medical communities as they are a means of networking with colleagues around the globe, discussing hot topics in various fields, engaging in medical education, sharing experiences through narrative medicine, and disseminating information to the lay-public [4]. More recently, social media has also taken on a vital role in residency recruitment. Without in-person interviews, programs have had to adopt new methods of sharing program strengths, highlighting unique program qualities, and appealing to applicants at an individual level [5]
We are avid proponents of academic social media. We can anecdotally attest to the educational value that arises from academic posts and discourse on social media platforms. Twitter, for example, offers a highly diverse pool of opinions covering all niches of medicine. It allows communication between individuals who might otherwise never interact. Sharing articles of interest via "tweeting" brings primary literature to your network's fingertips. Twitter brings full professors and first-year medical students into the same arena of idea sharing. In a world that has increasingly recognized the shortcomings of traditional didactic lectures, social media offers modern educational methods better suited for today's learners. Examples of this include "Tweetorials" (educational threads exploring a particular topic or phenomenon), podcasts, infographics, blogs, and virtual journal clubs among others [4].

These innovative methods of education through social media are intriguing to passionate educators. Those who seek to share knowledge and contribute to the advancement of scholarship will teach in whatever methods are most effective and will reach the most pupils. Importantly, social media is free, offering accessible medical education in a climate rife with expensive online materials and rising tuition. The value of these academic 
contributions must not go unrecognized. The time and dedication that goes into the development of educational posts through innovative methods should not be left out of an individuals' portfolio simply because the medium is not classic. If anything, the ingenuity and adaptability of the medium creates added value to the material. As the face of education evolves with our digital world, propelled forward by the COVID-19 pandemic, academia must evolve in unison to recognize these contributions.

We are thankful to Acquaviva and associates [1] for providing us with much-needed guidelines that allow for the documentation of education portfolios representative of today's evolving medical education environment.

\title{
Editorial Notice
}

The corresponding author of "Documenting Social Media Engagement as Scholarship: A New Model for Assessing Academic Accomplishment for the Health Professions" declined to respond to this letter.

\section{Conflicts of Interest}

None declared.

\section{References}

1. Acquaviva KD, Mugele J, Abadilla N, Adamson T, Bernstein SL, Bhayani RK, et al. Documenting Social Media Engagement as Scholarship: A New Model for Assessing Academic Accomplishment for the Health Professions. J Med Internet Res 2020 Dec 2;22(12):e25070 [FREE Full text] [doi: 10.2196/25070] [Medline: 33263554]

2. Spieler B, Ballard DH, Mazaheri P, Legro N, Catanzano T, Dey C, et al. Social Media in Radiology: Overview and Usefulness of Online Professional \#SoMe Profiles. Acad Radiol 2021 Apr;28(4):526-539. [doi: 10.1016/j.acra.2020.03.014] [Medline: 32482471]

3. Mullins CH, Boyd CJ, Corey BL. Examining the Correlation Between Altmetric Score and Citations in the General Surgery Literature. J Surg Res 2020 Apr;248:159-164. [doi: 10.1016/j.jss.2019.11.008] [Medline: 31901796]

4. Sterling M, Leung P, Wright D, Bishop TF. The Use of Social Media in Graduate Medical Education: A Systematic Review. Acad Med 2017 Jul;92(7):1043-1056 [FREE Full text] [doi: 10.1097/ACM.0000000000001617] [Medline: 28225466]

5. Heitkamp NM, Morgan LE, Carmody JB, Heitkamp DE. Pediatric Program Directors Should Have an Active Presence on Twitter. Acad Pediatr 2021 Mar;21(2):201-204. [doi: 10.1016/j.acap.2020.11.016] [Medline: 33227535]

\section{Abbreviations \\ CV: curriculum vitae}

\author{
Edited by T Derrick; this is a non-peer-reviewed article. Submitted 01.02.21; accepted 13.05.21; published 09.06.21. \\ Please cite as: \\ Gambril JA, Boyd CJ, Egbaria J \\ The Numerous Benefits of Social Media for Medicine. Comment on "Documenting Social Media Engagement as Scholarship: A New \\ Model for Assessing Academic Accomplishment for the Health Professions” \\ J Med Internet Res 2021;23(6):e27664 \\ URL: https://www.jmir.org/2021/6/e27664 \\ doi: $10.2196 / 27664$ \\ PMID:
}

CJohn Alan Gambril, Carter J Boyd, Jamal Egbaria. Originally published in the Journal of Medical Internet Research (https://www.jmir.org), 09.06.2021. This is an open-access article distributed under the terms of the Creative Commons Attribution License (https://creativecommons.org/licenses/by/4.0/), which permits unrestricted use, distribution, and reproduction in any medium, provided the original work, first published in the Journal of Medical Internet Research, is properly cited. The complete bibliographic information, a link to the original publication on https://www.jmir.org/, as well as this copyright and license information must be included. 